\title{
WEAR BEHAVIOUR OF DUPLEX (PN+PVD) TREATED LAYERS PRODUCED ON X42CR13 STEEL
}

\author{
Shiraz Ahmed Siddiqui \\ PhD Student, University of Miskolc, Hungary \\ Institute of Materials Science \& Technology \\ 3515 Miskolc, Miskolc-Egyetemváros, email: shiraz.ahmed@uni-miskolc.hu \\ Maria Berkes Maros \\ Associate Professor (Dr. habil.), University of Miskolc, Hungary \\ Institute of Materials Science \& Technology \\ 3515 Miskolc, Miskolc-Egyetemváros, email: maria.maros@uni-miskolc.hu
}

\begin{abstract}
Wear, corrosion and fatigue are among the most important mechanisms that lead to surface damage, which, ultimately, leads to failure of the components. There is an increasing demand for reducing failures and the related costs due to wear and surface shortcomings of heavily loaded engineering components. Thus, application of surface technologies gives a great potential for saving resources and providing improved technology.

The presented research work involves characterization of a duplex treated i.e. plasma nitrided (at two different temperatures $520{ }^{\circ} \mathrm{C}, 550^{\circ} \mathrm{C}$ ) and PVD coated - X42Crl3/W plastic mould tool steel with special emphasis on the ball-on-disc wear behaviour of tested specimens. The objective is to study and evaluate the effect of different nitriding treatments prior to coating on the wear behaviour of specimens having different surface preparations. Also, it has been established that duplex treatment (plasma nitriding + physical vapour deposition - PVD - coating) gives better and improved properties as compared to individual treatments.
\end{abstract}

Keywords: Wear, Duplex heat treatment, Plasma nitriding, PVD coating, Ball-on-disc test

\section{Introduction}

The annual loss by material degradation, owing to wear mechanism alone is assessed at $7-8 \%$ of a nation's gross national product (GNP) [1]. Surface treatments (thermochemical heat treatments and coatings) of components are of great importance for industry: the mechanical properties (hardness, wear and fatigue resistance) and corrosion resistance of the surface layer of treated parts can be improved considerably, due to the chemical and structural changes induced by these processes in the surface region of the treated parts [1]. Nitriding is a commonly used thermochemical method that involves the diffusion of the nascent nitrogen into the surface of steels and cast irons [2-4]. Plasma (ion) nitriding is a surface hardening process based on the principle of glow discharge technology [58].

In tribological applications, the PVD coating is an effective and innovative technology to reduce friction and to protect the surface from wear and corrosion. Coatings improve the performance of the tribological system in many ways, for instance by decreasing the friction coefficient, increasing the surface hardness or changing the surface texture $[9,10]$. DLC (diamond-like carbon) is one of the most effective types of coating reducing the friction coefficient to much greater extent comparing to other superhard coatings. 
Wear is a phenomenon that occurs in frictional loading conditions, causing material loss and surface degradation of materials, decreasing the lifetime of machining tools or increasing the risk of failures, etc. [11]. From the point of view of characteristic loadings or environmental reactions, surface is regarded as the most critical part of machine elements. The wear of the mechanical components has a significant economic impact.

Duplex treatment is one of the innovative surface technologies that have received immense exploitation in the field of automotive and aviation industry, biomedical applications, surgery, etc. this is the reason for researchers to focus topics, which are related to duplex surface technologies and its application potential [12-13]. The presented research work has a great potential in improving the wear resistance, increasing loadability, expanding the service life, durability of the components. Applying this technique, we can develop unique combination of mechanical characteristics, which has valuable impact on the property design of the surface and substrate together and results in costeffective performance enhancement of materials and components [14-16].

\section{Experimental Work}

The aim of the current research work consists in characterizing the influence of the duplex treatment applied onto the investigated $\mathrm{X} 42 \mathrm{Cr} 13 / \mathrm{W}$ tool steel and most importantly to compare the effect of the different nitriding treatments on the wear behaviour of specimens having polished $(\mathrm{P})$ or glass bead blasted (GBB) substrate surface below the PVD produced DLC coating.

\subsection{Investigated Material}

The specimen is made of a high alloyed plastic mould tool steel X42Cr13/W (DIN) Nr. 1.2083. The standard chemical composition is given in Table 1.

Table 1. Standard chemical composition in weight \%; EN ISO 4957:2001, DIN 17350 (1980)

\begin{tabular}{|c|c|c|c|c|c|c|}
\hline $\mathrm{C}$ & $\mathrm{Si}$ & $\mathrm{Mn}$ & $\mathrm{P}$ & $\mathrm{S}$ & $\mathrm{Cr}$ & $\mathrm{Fe}$ \\
\hline $0.38-0.45$ & Max 1.0 & Max 1.0 & Max 0.030 & Max 0.030 & $12.00-13.50$ & Bal. \\
\hline
\end{tabular}

\subsection{Sample processing and nitriding}

The disc shaped samples were cut from a steel rod with diameter of $50 \mathrm{~mm}$ and height of $10 \mathrm{~mm}$. Then grinding operation was performed to provide parallel surfaces required by the planned mechanical and microstructural investigations. Precipitation hardening $(\mathrm{PH})$, providing the characteristic high strength of the tool material was applied on each sample. A part of the samples was nitrided, e. g. surface treated. For these specimens, the surface treatment process was preceded by a surface finishing operation, i.e. by a second grinding to provide clean surfaces of the discs, with the aim of improving the efficiency of the surface treatment.

The nitriding process was performed applying gas nitriding, using the following technological parameters:

- Temperature: $520^{\circ} \mathrm{C}, 550{ }^{\circ} \mathrm{C}$,

- Holding time: 8 hours;

- Pressure: 2 mbar $=200 \mathrm{~Pa}$; 
- Voltage: $600 \mathrm{~V}$;

- Source of nitrogen: decomposed ammonia.

\subsection{Surface preparation and coating}

The specimens had three surface treatment conditions before PVD coating, i.e. untreated, nitrided at $520^{\circ} \mathrm{C}$ and nitrided at $550^{\circ} \mathrm{C}$.

The surface of the substrate material has been differently prepared before the coating procedure:

- Surface preparation I.: Polishing (to get a polished surface of the samples before PVD);

- Surface preparation II.: Glass bead blasting (to clean the surface before PVD).

The specimens investigated in this research work had different combinations of the abovementioned surface treatment and surface preparation conditions, as well as they had or didn't have PVD coating. The coating was a DLC layer, getting recently wider industrial applications. The calculated layer thickness is $2.3517 \mu \mathrm{m}$. The tested variations of the conditions are listed in Table 2 .

Table 2. The investigated combinations of the applied bulk heat treatment, surface preparation and PVD coating

\begin{tabular}{|c|c|c|c|c|c|}
\hline $\begin{array}{c}\text { Probe } \\
\text { number }\end{array}$ & Nitriding & PVD & $\begin{array}{c}\text { Surface } \\
\text { preparation } \\
\text { before PVD }\end{array}$ & $\begin{array}{c}\text { Sample condition } \\
\text { nomination }\end{array}$ & $\begin{array}{c}\text { Colour } \\
\text { code }\end{array}$ \\
\hline P13 & - & Yes & Polished & P+PVD & \\
\hline P14 & - & Yes & Grinded & GBB+PVD & \\
\hline P15 & $550{ }^{\circ} \mathrm{C}$ & Yes & Polished & $\mathrm{N}\left(550^{\circ} \mathrm{C}\right)+\mathrm{P}+\mathrm{PVD}$ & \\
\hline $\mathrm{P} 16$ & $550^{\circ} \mathrm{C}$ & Yes & Grinded & $\mathrm{N}\left(550^{\circ} \mathrm{C}\right)+\mathrm{GBB}+\mathrm{PVD}$ & \\
\hline $\mathrm{P} 17$ & $520^{\circ} \mathrm{C}$ & Yes & Grinded & $\mathrm{N}\left(550^{\circ} \mathrm{C}\right)+\mathrm{GBB}+\mathrm{PVD}$ & \\
\hline $\mathrm{P} 18$ & $520^{\circ} \mathrm{C}$ & Yes & Polished & $\mathrm{N}\left(550^{\circ} \mathrm{C}\right)+\mathrm{P}+\mathrm{PVD}$ & \\
\hline
\end{tabular}

\subsection{Ball-on-disc test}

Ball-on-disc test was carried out to evaluate the wear behaviour of the samples. This was done by UNMT-1 tester at the laboratory of Institute of Materials Science and Technology (Figure 1). The UNMT-1 is a fully automated and computerized tribology tester with proprietary software control in a user-friendly windows environment [17].

To evaluate and compare the tribological performance of the different samples, the coefficient of friction - which is one of the essential characteristics of a tribo-system - was calculated based on the measuring the tangential and normal force during ball-on-disc wear tests.

The ball-on-disc tests were accomplished using the following test parameters:

- material of ball: $\mathrm{SiC}$, diameter $6 \mathrm{~mm}$;

- normal force: $\mathrm{F}=90 \mathrm{~N}$;

- total sliding distance: $\mathrm{L}=180 \mathrm{~m}$ (based on $360 \mathrm{~m}$ preliminary wear test it was observed that the steady state friction coefficient can be achieved already at $180 \mathrm{~m}$ );

- diameter of the wear track: $\mathrm{d}=6 \mathrm{~mm}$. 
The ball-on-disc test machine records on-line the friction coefficient value.

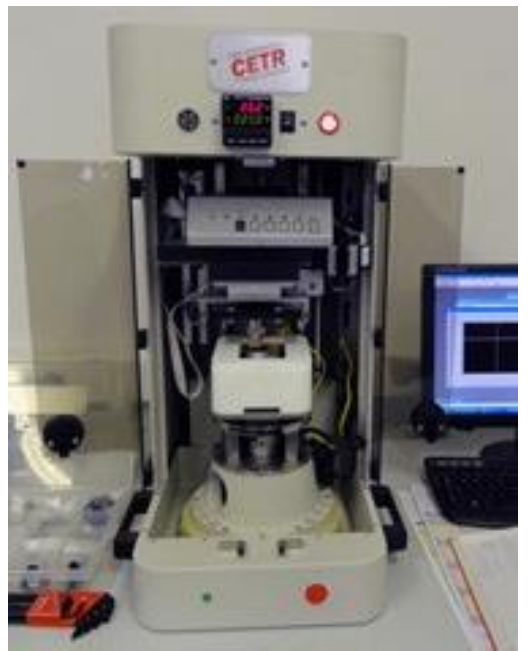

Figure 1. UNMT-1 (producer: CETR) equipment used to perform ball-on-disc test

\section{Results and Discussion}

\subsection{Comparison of the effect of different nitriding treatments on the friction behaviour of specimens with polished surface below the PVD coating (P+PVD samples)}

Each specimen was polished before the application of the PVD coating. Figure 2 illustrates the wear test diagrams - i.e. the friction coefficient vs. sliding distance - for samples having different nitriding conditions prior to PVD coating.

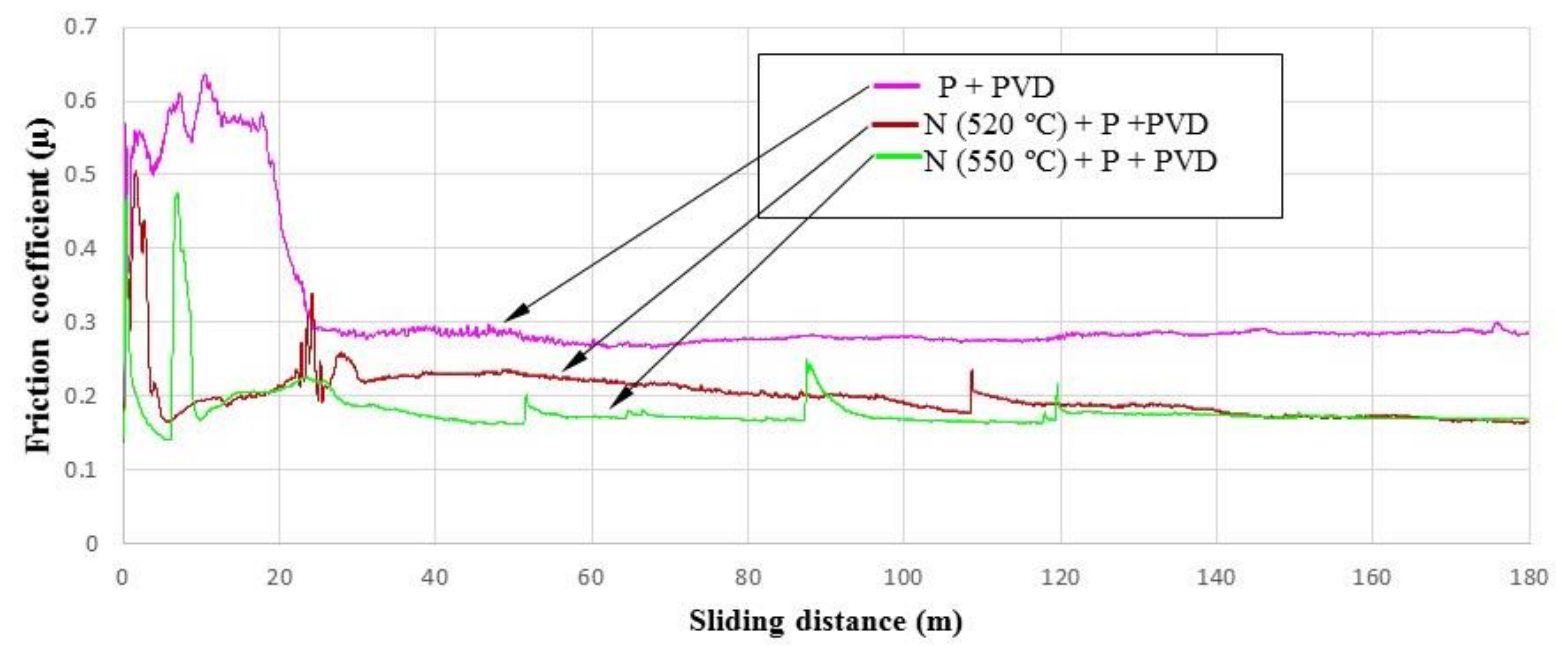

Figure 2. Friction behaviour of differently treated samples with polished surface below the PVD layer 
The related values of the steady state friction coefficient $\left(\mu_{\mathrm{sS}}\right)$ are shown in Figure 3 . It is seen that in case of the un-nitrided specimen (P+PVD) the friction coefficient has the highest value, while the steady state friction coefficients of the samples nitrided at $550{ }^{\circ} \mathrm{C}-$ marked $\mathrm{N}\left(550^{\circ} \mathrm{C}\right)+\mathrm{P}+\mathrm{PVD}-$ and nitrided at $520^{\circ} \mathrm{C}-$ marked $\mathrm{N}\left(520^{\circ} \mathrm{C}\right)+\mathrm{P}+\mathrm{PVD}$ are unambiguously lower. From this it clearly follows that duplex treatment is advantageous from the point of view of reducing the friction, i.e. combination of plasma nitriding and PVD coating gives better results.

In Figure 2, it is also seen that there is no significant difference between the friction coefficient curves of the two duplex treated samples. Here should be mentioned that the average of the nitrided layer depth for samples nitrided at $520^{\circ} \mathrm{C}$ is $0.142 \mathrm{~mm}$ and for samples nitrided at $550{ }^{\circ} \mathrm{C}$ is $0.197 \mathrm{~mm}$. Though the difference between the two nitrided depths is closely $40 \%$, it has no significant effect from the practical point of view, leading to closely similar friction behaviour. Altogether nitriding before PVD coating helps to decrease the coefficient of friction.

In the friction coefficient curve of the sample $\mathrm{N}\left(550^{\circ} \mathrm{C}\right)+\mathrm{P}+\mathrm{PVD}$ some periodically appearing peaks are visible (Figure 2). The reason behind it is the possibility of formation and presence of some debris originated probably from the removed surface layer and the $\mathrm{SiC}$ ball, leading to a kind of stickslip motion of the frictional counterparts. Along the first 10-20 meters of the sliding distance in the friction coefficient curves an appreciably increased friction coefficient can be observed, which indicates the damage of the coating. The length of this region for the simply coated sample is longer than for the duplex treated ones, since the nitrided layers give a stable support for the coating. A slighter damage also can be seen on the optical microscopic image of the wear tracks (Figure 3).

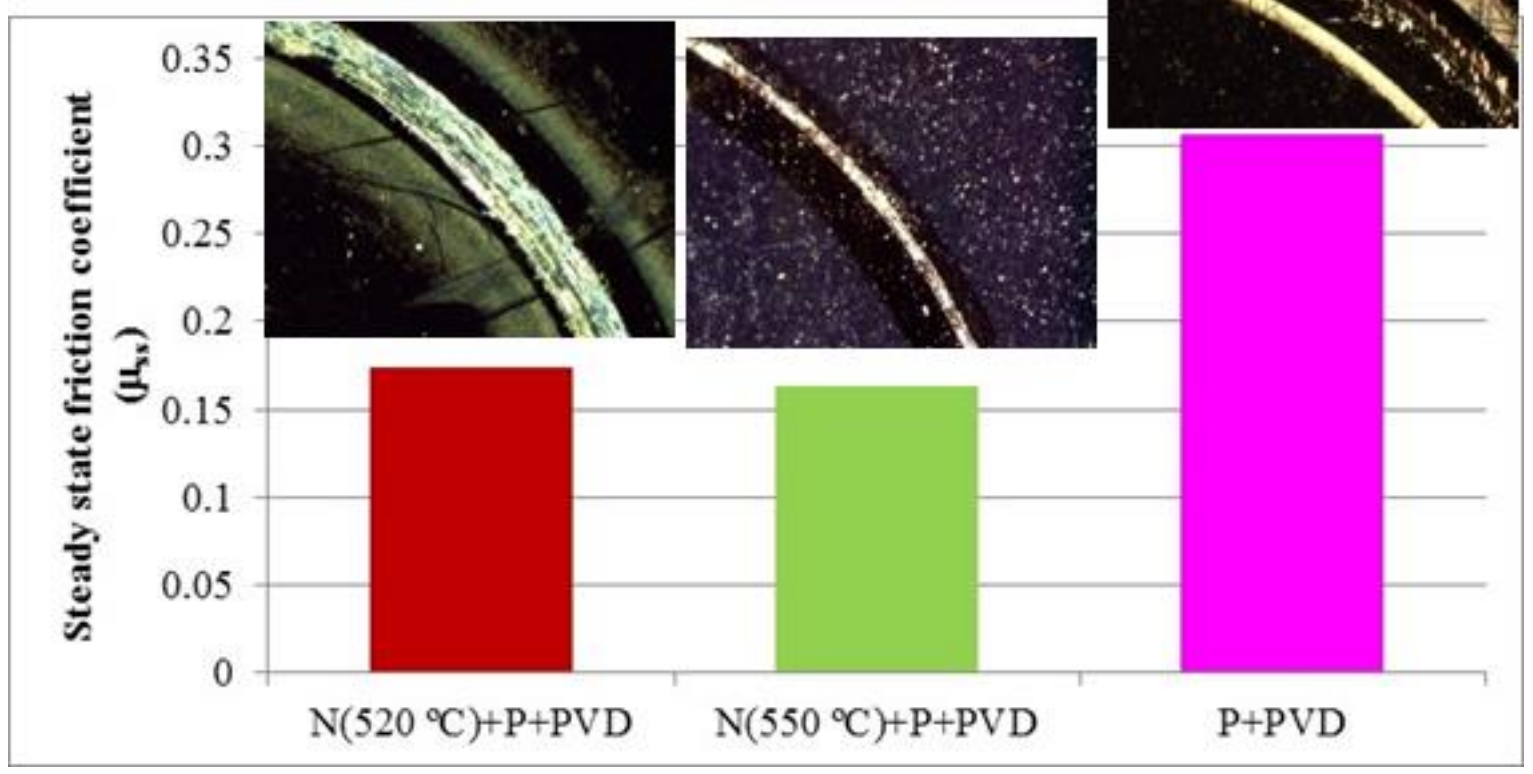

Figure 3. Steady state friction coefficient and appearance of the wear track of differently treated samples having polished surface below the PVD layer 


\subsection{Comparison of the effect of the different nitriding treatments on the friction behaviour of specimens with glass bead blasted (GBB) surface below the PVD coating (GBB+PVD samples)}

In this case, each specimen was glass bead blasted before the application of the PVD coating and the specimens had the same treatment conditions - e.g. un-nitrided and nitrided at 520 and $550{ }^{\circ} \mathrm{C}$. Figure 4 illustrates the related friction coefficient vs. sliding distance curves.

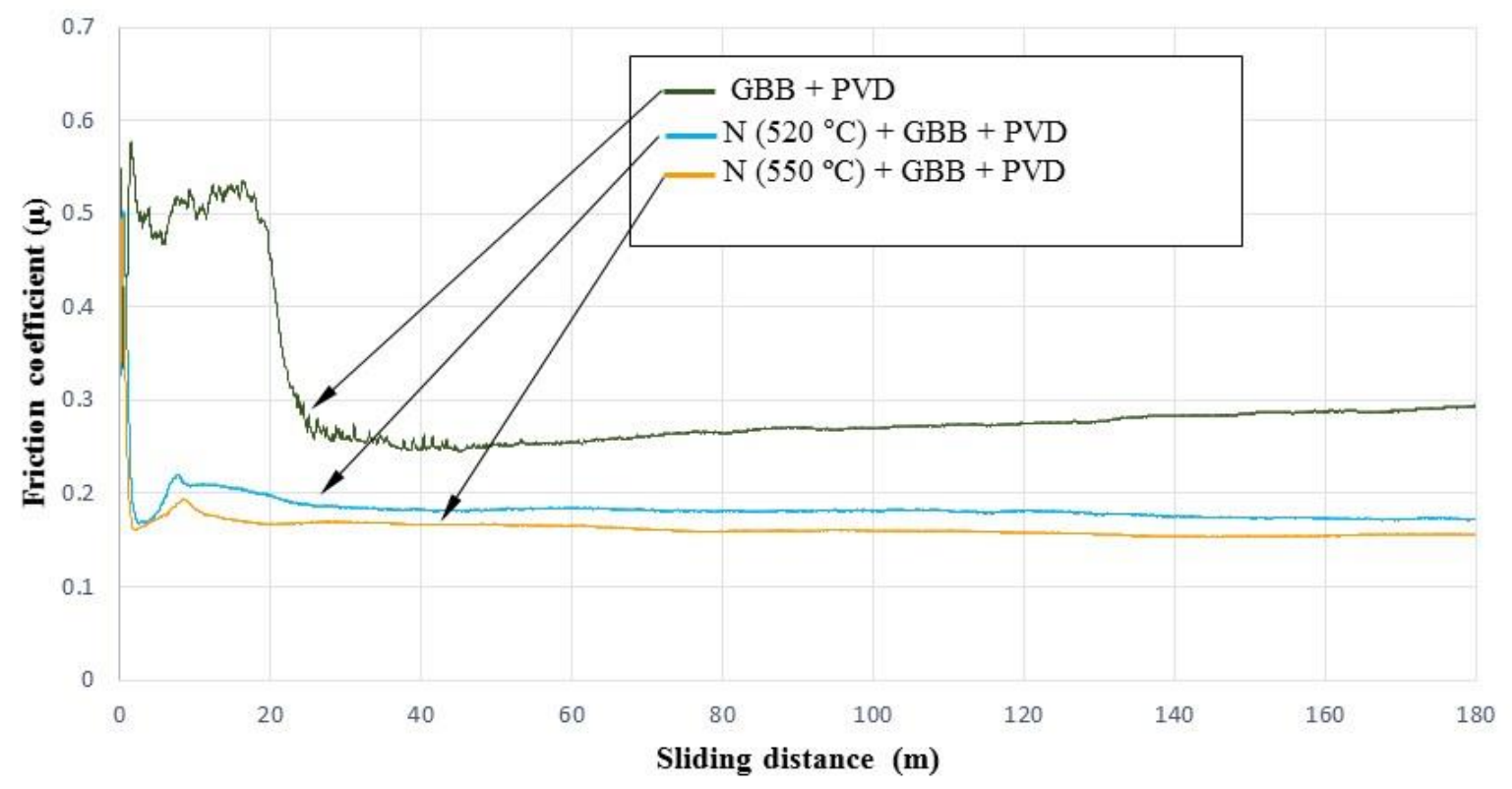

Figure 4. Friction behaviour of differently treated samples having GBB surface below the PVD layer

The friction coefficient curves related to the duplex treated specimens are smooth and not increasing along the entire sliding distance. The coating is just partially removed, as seen in the wear track pictures, taken by optical microscope (Figure 5). Similarly to the cases experienced with the polished samples, at the initial $20 \mathrm{~m}$ of the sliding distance a transient behaviour can be observed on the friction coefficient curves (Figure 4), which is more clearly expressed in case of the GBB+PVD sample indicating that the superhard DLC layer is more easily damaged without a hard supporting layer compared to the duplex treated layers.

After the coating is partially detached the curve has more and more smooth shape reaching the steady state value of the friction coefficient, that is the highest in case of the un-nitrided (GBB+PVD) sample and significantly lower for the duplex treated samples. In general, the higher is the value of $\mu$, the lower is the resistance to friction and higher is the degree of surface deterioration.

Based on these observations, it can be established that lower friction coefficient is reached, and assumingly higher wear resistance can be obtained on duplex treated samples even in case of GBB surface preparation. i. e. nitriding before PVD coating is always beneficial independently of these surface preparations leading to better wear resistance and lower value of friction coefficient as compared to the un-nitrided, but PVD coated sample. 


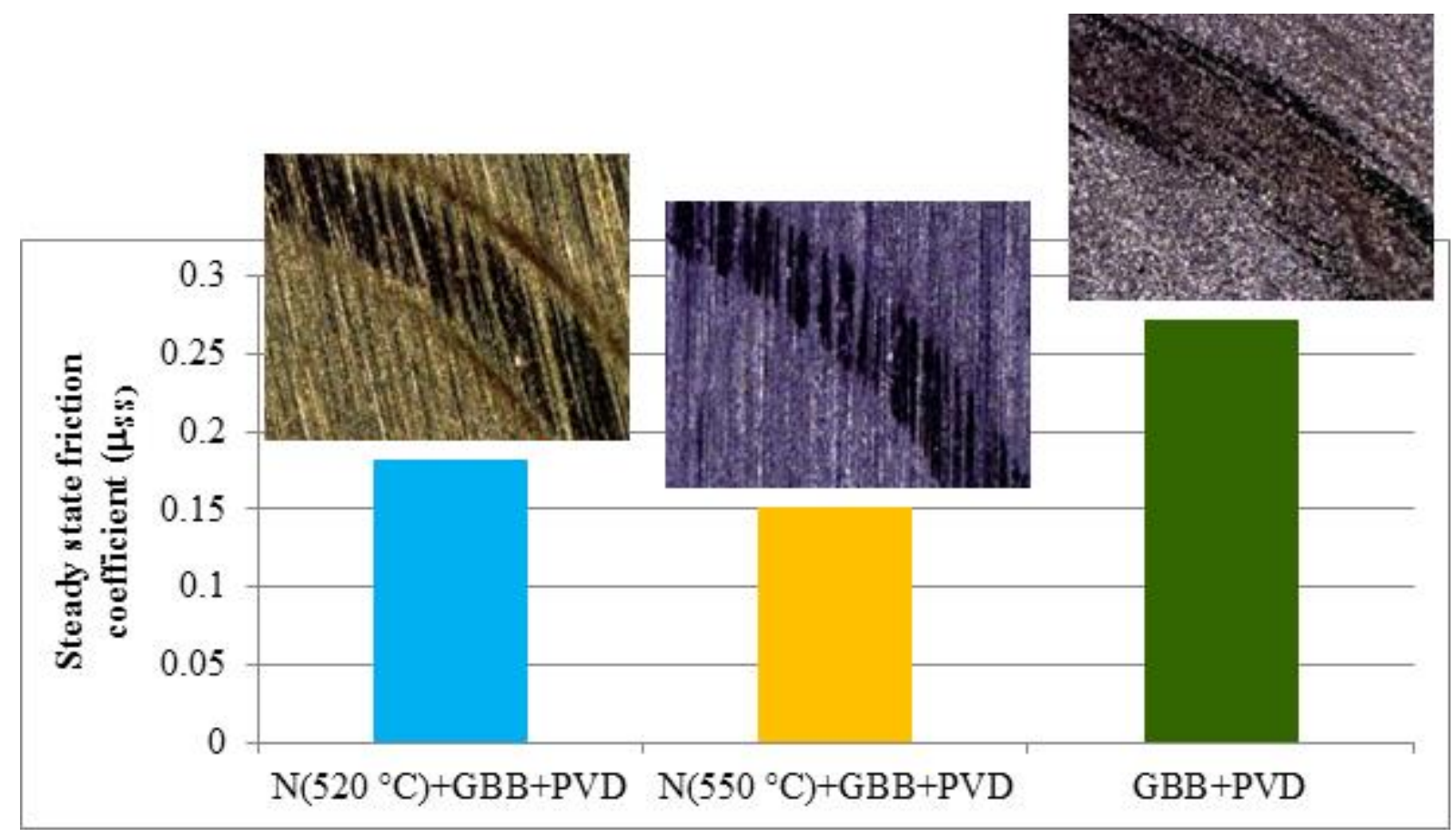

Figure 5. Steady state friction coefficient and the wear track on differently treated samples having glass bead blasted surface below PVD layer

\subsection{Summarizing the effect of the thermochemical treatments:}

- Without coating, the value of the steady state friction coefficient would reach $0.6-0.7$ (the related test results not reported here) while in case of the applied PVD produced DLC coatings the value of $\mu_{\mathrm{SS}}$ decreased significantly, up to $0.16-0.30$.

- The higher values $(0.27$ and 0.3$)$ were obtained for the simply coated samples with un-nitrided substrate, while the lowest $\mu_{\mathrm{ss}}$ values (0.16-0.18) characteristic for the DLC layers could be reached if we provided enough support for the superhard coating layer by nitriding in the form of duplex treatment.

\subsubsection{For samples that were polished before the PVD (designated by P+PVD):}

- To obtain lower friction coefficient and presumably better wear behaviour under the applied test conditions a nitriding treatment is suggested to be carried out at the higher investigated temperature (i.e. $550^{\circ} \mathrm{C}$ ) followed by polishing and PVD coating.

- Application of the studied combined surface technology, i.e. the duplex treatment (PN+PVD) can be advantageous to get better wear resistance and tribological properties. 


\subsubsection{For samples that were glass bead blasted (designated by GBB+PVD):}

- Nitriding prior to PVD coating decreases the friction coefficient providing better surface conditions in frictional loading as compared to un-nitrided, PVD coated samples.

- If GBB surface preparation procedure was applied on the substrate material before the PVD coating similar $\mu$ values were obtained compared to cases when polishing was used. However, the shape of the friction coefficient curve during ball-on-disc test was more uniform for the GBB prepared samples, so the wear behaviour is expected to be more stable applying this surface preparation procedure.

\section{Conclusions}

Based on the results of the accomplished ball-on-disc test and the related observations, we can conclude the followings:

- The most important conclusion of our study is that the applied duplex treatments resulted in systematically better wear performance that manifested itself in a lower coefficient of friction and less damage to the DLC coating layer, as compared to the un-nitrided, PVD coated sample with the same DLC coating.

- The applied duplex treatments involved two different nitriding procedures (at $520^{\circ} \mathrm{C}$ and $550{ }^{\circ} \mathrm{C}$ ) before the PVD produced DLC coating. Better wear resistance, lower steady state coefficient of friction and better integrity of the DLC coating could always be experienced if nitriding temperature was higher $\left(550^{\circ} \mathrm{C}\right)$, providing a stronger support for the superhard DLC coating.

- The effect of the surface treatments of substrate material on the friction behaviour of the PVD coated samples were similar either glass bead blasting, or polishing were carried out on the surface prior to PVD coating, i.e. the obtained friction coefficient values were independent of the surface preparation, while they were clearly dependent on the surface heat treatment conditions.

\section{Acknowledgements}

This research was supported by the European Union and the Hungarian State, co-financed by the European Regional Development Fund in the framework of the GINOP-2.3.4-15-2016-00004 project, aimed to promote the cooperation between the higher education and the industry.

The research reported here was carried out as part of the EFOP-3.6.1-16-2016-00011 "Younger and Renewing University - Innovative Knowledge City - Institutional development of the University of Miskolc aiming at intelligent specialization" project implemented in the framework of the Széchenyi 2020 program. The realization of this project is supported by the European Union, co-financed by the European Social Fund. 


\section{References}

[1] Mittemeijer, E. J., Somers, M. A. J.: Thermochemical Surface Engineering of Steels, Woodhead Publishing. ISBN 978085709592, 2014, Chapter 1, pp. 23-25. https://doi.org/10.1016/C2013-0-16318-0

[2] Pye, D.: Practical Nitriding and Ferritic Nitrocarburizing, ASM International, 2003, ISBN 087170-791-8, Chapter 1, pp.15-18.

[3] Bell, T., Bardet, W. P.: Surface Engineering, ASM International Handbook, Vol. 5, 1994. pp. 1800-1810.

[4] Kocsisné, B. M., Marosné, B.M., Szilágyiné, B. A. (ed.): Nitridálás - korszerü eljárások és vizsgálati módszerek, Miskolci Egyetem (2015) 296.p. ISBN 9789633580806

[5] Xu, D. Z., Xiong F. F.: Plasma Surface Metallurgy, Springer Nature, 2017, pp.13-21. https://doi.org/10.1007/978-981-10-5724-3_2

[6] Xu, D. Z., Liu, X. P., Zhang, P., Zhang, Y., Zhang, G., He, Z. Double Glow Plasma Surface Alloying and Plasma Nitriding, Surface and Coatings Technology, 201 (2007) pp.4822-4825. https://doi.org/10.1016/j.surfcoat.2006.07.187

[7] Yagita, K. Ohki, C.: Plasma Nitriding Treatment of High Alloy Steel for Bearing Components, NTN Technical Review 78 (2010) pp.2-6.

[8] Szilágyiné, B. A.: Active Screen Plasma Nitriding - State of the Art, Production Processes and Systems 7 No.1 (2014) pp.103-114.

[9] Holmberg, K., Matthews, A.: Coatings Tribology - properties, techniques and applications in surface engineering, Elsevier Tribology Series 28, Elsevier Science, the Netherlands, 1994. pp. 442.

[10] Caruta, B. M.: Thin Films and Coatings: New research. Nova Science Publishers, New York, ISBN 1-59454-517-0

[11] Bhushan, B.: Introduction to tribology, John Wiley Publications, 2013. ISBN 978-1-11994453-9, Chapter 7, pp. 331-345.

[12] Donnet, C., Erdemir, A.: Historical Developments and New Trends in Tribological and Solid Lubricant Coatings, Surface and Coatings Technology 180-181 (2004) pp.76-84. https://doi.org/10.1016/j.surfcoat.2003.10.022

[13] Podgornik, B., Vizintin, J., Wanstrand, O., Larrson, M., Hogmark, S.: Wear and Friction Behaviour of Duplex Treated AISI 4140, Steel Surface and Coating Technology 120-121 (1999) pp.502-508. https://doi.org/10.1016/S0257-8972(99)00417-X

[14] Sun, Y., Bell. T.: Combined Plasma Nitriding and PVD Treatment, Transaction of the IMF 70 No.1 (1992) pp.38-44. https://doi.org/10.1080/00202967.1992.11870939

[15] Surzhenkov, A., Podra, P., Sergejev, F., Saarna, M., Adoberg, E., Mikli, V., Viljus, M., Kulu, P. Comparative Study of the PVD coatings on Plasma Nitrided Steel, Materials Science 18 (2012) pp.40-44. https://doi.org/10.5755/j01.ms.18.1.1339

[16] Feldman, L. L., Mayler, J. W.: Fundamentals of Surface and Thin Film Analysis. New York, London Elsevier Science Publisher, 1986, ISBN 0135005701

[17] Cetrtribology.com/eng/services/products-umt.html (download: 06.07.2018) 